\title{
Тенденции в избирательности браков по уровню образования: роль изменений в образовательной структуре населения
}

\author{
Д.И. ЗИНЧЕНКО*, А.Л. ЛУКЬЯНОВА**
}

*Дарья Игоревна Зинченко - стажер-исследователь, Центр трудовых исследований, Национальный исследовательский университет «Высшая школа экономики». Адрес: 110100, Москва, ул. Мясницкая, д. 20. E-mail: dzinchenko@hse.ru

**Анна Львовна Лукьянова - кандидат экономических наук, старший научный сотрудник, Центр трудовых исследований, Национальный исследовательский университет «Высшая школа экономики». Адрес: 110100, Москва, ул. Мясницкая, д. 20. E-mail: alukyanova@hse.ru

Цитирование: Зинченко Д.И., Лукьянова А.Л. (2021) Тенденции в избирательности браков по уровню образования: роль изменений в образовательной структуре населения // Мир России. Т. 30. № 1. С. 111-133. DOI: 10.17323/1811-038X-2021-30-1-111-133

В работе, основанной на данных РМЭЗ ВШЭ за 1995-2015 г2., анализируется влияние роста уровня образованности российского населения на состояние в браке и изменение состава семей с точки зрения уровня образования супругов. Результаты показывают снижение доли состоящих в браке для обоих полов, всех образовательных и практически всех возрастных групп, при этом увеличение доли одиноких не является прямым следствием трендов в сфере образования. Выявлено, что изменения в образовательном составе населения сдерживали сокращение доли состоящих в браке благодаря росту удельного веса высокообразованных групп, в которых выше процент состоящих в браке. В структуре браков наблюдалось увеличение доли союзов, в которых мужья имеют более низкий уровень образования (гипогамия). Распространение таких браков происходило за счет сокращения доли пар, в которых партнеры имеют одинаковое образование, хотя последний тип союзов по-прежнему остается самым распространенным видом брака. Корректировка на тренды в образовательной структуре населения позволяет сделать вывод, что для большинства возрастных групп изменения в образовательной структуре являлись главным драйвером усиления гипогамии.

1 Исследование выполнено при финансовой поддержке РФФИ в рамках научного проекта № 19-310-90071. Авторы выражают признательность В. Захарову, В. Гимпельсону, Н. Калмыковой за полезные замечания и комментарии. 
Ключевые слова: уровень образования, гендер, супружеские пары, ассортативность браков, брачный статус, гомогамия

\section{Введение}

Одной из важных составляющих демографической модернизации является замена внешнего контроля над брачным и семейным поведением людей со стороны нормативных ограничений и социальных институтов внутренним самоконтролем. Россия постепенно движется к современному типу брака, в основе которого лежит свободный выбор и рациональные мотивы. В сфере брачно-семейных отношений модернизация выражается в отходе от традиционной модели ранней и всеобщей брачности. Формирование семьи начинается в более зрелом возрасте, увеличивается распространенность незарегистрированных браков, одновременно увеличивается доля лиц, никогда не состоявших в браке [Захаров 2007].

В настоящей работе затрагивается один из аспектов брачного поведения - связь между образованием и брачным статусом, а также сходство и различие между супругами по уровню имеющегося образования. Интерес к взаимосвязи между образованием и брачным поведением обусловлен двумя обстоятельствами. Во-первых, начиная со второй половины XX в. мир включился в образовательную гонку, которая выражается в постоянном увеличении доли населения с третичным, прежде всего высшим, образованием [Schofer, Meyer 2005]. Россия становится одним из мировых лидеров этой гонки: по данным переписей населения, доля лиц с высшим образованием среди населения 15 лет и старше выросла с 11,3\% в 1989 г. до 25,8\% в 2015 г. Во-вторых, уровень образования женщин растет опережающими темпами, что привело к появлению диспропорций в образовательной структуре мужского и женского населения. При этом в России перелом в структуре образования в пользу женщин произошел значительно раньше, чем в большинстве стран. В развитых странах число девушек, обучающихся в вузах, превзошло соответствующее число юношей во второй половине 1980-х - 1990-е гг. [Esteve et al. 2016]. В России для когорт, родившихся в конце 1950-х гг., охват женщин высшим образованием заметно превышал соответствующий показатель среди мужчин [Бессуднов и дp. 2017]. Целями настоящей статьи являются оценка изменений в структуре населения по брачному статусу и в составе семей по уровню образования на основе данных РМЭЗ-ВШЭ за 1995-2015 гг., а также выделение вклада образовательных сдвигов в наблюдаемые изменения.

Изучение российского опыта представляет интерес как уникальное сочетание высокого уровня образования, сильного дисбаланса в структуре образования в пользу женщин на фоне незавершенной демографической модернизации и консервативных гендерных стереотипов. В контексте формирования новой модели брачно-семейных отношений исследование выбора брачных партнеров и структуры браков становится актуальным не только с аналитической точки зрения, но приобретает и практическую значимость с точки зрения выработки мер социальной политики, направленной на укрепление института семьи и сдерживание обострения социального неравенства.

Рост уровня образования и гендерные различия в образовательной структуре населения отражаются на демографическом поведении индивидов, 
в т. ч. на решениях о выборе партнера. Предшествующие эмпирические исследования показали, что в России как мужчины, так и женщины склонны выбирать партнера, имеющего тот же уровень образования [Рощин, Рощина 2008; Зинченко, Лукьянова 2018] 2. В данной работе мы рассматриваем не только супружеские пары, но и одиноких граждан, поскольку получение высшего образования оказывает влияние и на стимулы к вступлению в брак. Еще одной особенностью работы является анализ избирательности браков в разрезе возрастных групп.

\section{Почему рост образованности населения влияет на брачный статус и выбор партнера?}

В традиционном обществе основными источниками экономического выигрыша от вступления в брак являлись разделение труда между супругами и специализация одного из них на рыночном производстве, а другого - на производстве в домашнем хозяйстве [Becker 1973]. Для максимизации общей полезности супруг с более высокой ставкой заработной платы (муж) должен тратить больше времени на рынке труда, супруг с более низкой ставкой заработной платы (жена) - в домашнем производстве. Однако специализация - не единственный источник выгод от вступления в брак, дополнительная полезность возникает также в производстве семейных благ (сексуальные отношения, воспитание детей) и в совместном потреблении. Для максимизации выгод от брака в этих сферах важно сходство предпочтений супругов, что позволяет им легче договориться о количестве детей, методах воспитания, инвестициях в недвижимость, расходах на проведение досуга и т. д. [Lam 1988]. Совпадение предпочтений более вероятно, если супруги похожи между собой и по другим характеристикам, в т. ч. по уровню образования.

В 1950-1980-е гг. произошли события, способствовавшие радикальному изменению положения женщин в обществе и модернизации брачного поведения. Вследствие широкого внедрения бытовой техники, либерализации разводов, появления новых средств контрацепции, распространения феминистских идей и принятия антидискриминационных законов резко выросли выгоды женщин, полученные от выхода на рынок труда как в абсолютном выражении, так и по отношению к специализации на ведении домашнего хозяйства, а также наблюдается ослабление гендерных стереотипов и социальных норм. В то же время интенсивные технологические изменения последних десятилетий XX в., подтолкнувшие увеличение спроса на работников высокой квалификации и рост отдачи от образования, привели к увеличению экономических издержек «неравных» браков [Fernández et al. 2005].

Постепенно доминирующим типом семьи становится семья, в которой заняты оба супруга. Переход к такому типу сближает предпочтения мужчин

\footnotetext{
2 В отечественной литературе активно изучаются и другие аспекты избирательности браков, прежде всего их возрастной и этнический состав [Волков 2014; Сороко 2014]. Брачные установки отдельных социальных групп, таких как студенты вузов и молодежь, рассматривались в работах отечественных социологов [Гурко 2006; Гурко, Мамиконян 2018].
} 
и женщин в отношении желаемых характеристик супругов. По мере того, как заработная плата жены становится важным компонентом семейного дохода, характеристики, влияющие на доход женщины, увеличивают ее привлекательность на брачном рынке. Образование как составляющая человеческого капитала начинает приносить отдачу не только на рынке труда, но и на брачном рынке, причем обоим супругам [Chiappori et al. 2009]: на рынке труда оно обеспечивает более высокие заработки; на брачном рынке способствует заключению союза с более качественным кандидатом.

Социологи также отмечают, что социальная модернизация и развитие системы образования способствовали превращению образования в ключевой фактор социально-экономического статуса [Blossfeld 2009]. Молодые люди стали дольше оставаться в системе образования именно в тех возрастах, когда поиск партнера наиболее интенсивен и количество свободных партнеров максимально. Благодаря ступенчатому отбору в учебные заведения профессионального образования молодежь попадает в среду, снижающую издержки поиска и многократно повышающую шансы встретить потенциального партнера с тем же уровнем образования [Oppenheimer 1988; Nielson, Svarer 2009]. Вместе с тем массовое распространение высшего образования могло вести и к снижению его ценности в качестве характеристики, влияющей на выбор партнера. Образование стало менее элитарным, а контингент студентов - более пестрым, что увеличивает вероятность контактов с более разнообразным социальным окружением. Рост доступности высшего образования ведет и к значительной вариации в качестве образования. Эти процессы подрывают сигнальную и структурную функции образования и размывают связь между наличием диплома, доходами и общностью интересов, что могло стать причиной снижения роли образования при оценке потенциального партнера.

Описанные изменения стимулировали опережающий рост инвестиций женщин в образование. Исторически получение женщиной высшего образования означало сокращение финансовых стимулов для вступления в брак, снижение вероятности выйти замуж на протяжении жизни и более высокие риски остаться одинокой [Goldin et al. 2006]. В странах с низкой гендерной сегрегацией (Скандинавия, Западная Европа) происходит постепенное сближение предпочтений мужчин и женщин в отношении желаемых характеристик партнеров, хотя различия все равно остаются существенными [Van Bavel et al. 2018]. Получение женщиной высшего образования увеличивает вероятность вступить в брак (но в более позднем возрасте), снижает риски развода, а в случае развода - повышает шансы на повторный брак. При этом в ситуации дефицита высокообразованных мужчин женщины с высоким уровнем образованием предпочитают создавать семью с менее образованными партнерами, нежели оставаться одинокими [De Hauw et al. 2017]. Женщины с низким уровнем образования реже вступают в зарегистрированный брак: как правило, это происходит в более раннем возрасте, но отношения между партнерами чаще заканчиваются разрывом, поэтому значительную часть взрослой жизни женщины с низким уровнем образования проводят без партнера [Isen, Stevenson 2010].

Изменения в поведении мужчин не были столь значительными. Исследования показывают увеличение затрат времени на домашнюю работу и воспитание детей, однако масштабы этого прироста несопоставимы с увеличением занятости 
среди женщин [Goldscheider, Waite 1993]. Сокращение разрыва в заработных платах между мужчинами и женщинами привело к снижению доли мужчин, состоящих в браке, особенно в группах с низким уровнем образования [Autor et al. 2019]. Мужчины с высоким уровнем образования, хотя и улучшили свое положение относительно менее образованных представителей своего пола, в абсолютном выражении демонстрировали снижение склонности к созданию семьи [Lundberg et al. 2016]. Даже в условиях усиления гендерной асимметрии в сфере образования мужчины медленно отказываются от традиционной роли основного кормильца [De Hauw et al. 2017].

Рассмотренные выше экономические и социологические теории демонстрируют, что уровень образованности населения мог повлиять на образовательный состав супружеских пар, однако эмпирические исследования не выявили каких-либо универсальных стилизованных фактов даже для развитых стран [Schwartz 2013]. Нередко результаты анализа даже по одной стране зависят от выбора базы данных, детализации уровней образования и используемых показателей. При этом социологи чаще обнаруживают рост доли пар, в которых супруги имеют одинаковое образование или жена имеет более высокий уровень образования [Schwartz, Mare 2005] за счет снижения доли пар, в которых муж более образован, чем жена. В странах, где женщины в среднем имеют более высокий уровень образования, чем мужчины, гипогамия более распространена, чем гипергамия [Esteve et al. 2012]. Экономисты, как правило, более скептичны в интерпретации наблюдаемых трендов и считают, что ключевое значение в их формировании играют изменения в сфере образования, в то время как предпочтения индивидов в отношении образования супругов мало изменились на протяжении последних десятилетий [Gihleb, Lang 2016]. Кроме того, тренды нередко различаются для разных образовательных групп: так, в развитых странах частота равных браков увеличилась среди малообразованных индивидов и снизилась среди имеющих высшее образование [Eika et al. 2019].

Проведенный анализ литературы позволяет сформулировать следующие ожидаемые результаты относительно влияния роста образованности населения, прежде всего среди женщин, на брачный статус и образовательную избирательность браков в России:

- рост образованности населения ведет к снижению доли состоящих в браке за счет откладывания вступления в брак и сокращения экономической выгоды от брака;

- образование ведет к росту привлекательности высокообразованных партнеров (как мужчин, так и женщин); мы ожидаем увеличения разрыва в доле состоящих в браке между высоко- и низкообразованными группами;

- опережающий рост уровня образования женщин должен привести к увеличению доли гомо- и гипогамных браков за счет гипергамных браков;

- с учетом высокого уровня гендерной сегрегации, консервативных взглядов и значительного гендерного разрыва в оплате труда мы ожидаем, что ключевую роль в изменении образовательной избирательности браков сыграли тренды в сфере образования, в то время как предпочтения индивидов изменились незначительно;

- движущей силой изменений являются более молодые возрастные группы, которые испытали на себе влияние образовательного бума 1990-2000-х гг. 


\section{Данные и описание выборки}

Для анализа образовательной ассортативности браков в России в настоящей работе используются данные репрезентативной части выборки РМЭЗ ВШЭ за 1995-2015 гг.

В этом исследовании мы не проводим различий между зарегистрированными и незарегистрированными браками и используем термины «брак» и «партнерский союз», а также «супруги» и «партнеры» как синонимы. Анализ по другим странам указывает на то, что нельзя дать четких предсказаний относительно различий между зарегистрированными браками и неформальными союзами. В странах, где последние носят маргинальный характер, сходство партнеров по уровню образования оказывается ниже. Однако по мере того, как неформальные союзы получают более широкое распространение и (в ряде стран) законодательные гарантии, различия в образовательных структурах между зарегистрированными и незарегистрированными браками постепенно стираются [Schwartz 2010; Esteve et al. 2012]. Изменение формулировки вопроса о семейном положении в РМЭЗ ВШЭ в конце 1990-х гг. не позволяет нам однозначно разделить два вида браков для всех рассматриваемых раундов.

Выборка супружеских пар ограничена зарегистрированными и незарегистрированными браками, в которых оба партнера старше 18 лет, что соответствует минимальному возрасту вступления в брак в РФ, поэтому результаты исследования следует считать представительными для населения старше 18 лет $^{4}$. Из выборки были удалены наблюдения с отсутствующими сведениями об образовании и возрасте хотя бы одного из партнеров ${ }^{5}$. Наличие партнерских отношений устанавливалось на основе семейного вопросника РМЭЗ ВШЭ. Дизайн обследования позволяет учесть только те пары, которые проживают совместно в одном домохозяйстве; за рамками анализа остались союзы, в которых постоянные партнеры проживают раздельно. Такие индивиды присутствуют в выборке РМЭЗ ВШЭ: за все годы 3381 респондент (2\% от общего числа) в индивидуальных вопросниках ответили, что состоят в браке, но по семейному вопроснику в составе домохозяйств не было обнаружено их партнеров. Мы считали их не состоящими в браке.

При анализе брачных статусов мы расширяем выборку за счет лиц, не состоящих в браке, также с полной информацией по полу, возрасту и образованию. Лица, не состоящие в браке, включают в себя никогда не состоявших в браке, разошедшихся, разведенных, вдовых и не проживающих в одном домохозяйстве с партнером. Расширенная выборка включает 168674 респондента, в т. ч. 101898 состоящих в браке. Заметим, что в выборке присутствуют как те, кто вступил в партнерские отношения недавно, так и те, кто состоит в браке уже много лет. Наблюдаемая

\footnotetext{
3 Российский мониторинг экономического положения и здоровья населения НИУ ВШЭ, проводимый НИУ ВШЭ и ООО «Демоскоп» при участии Центра народонаселения Университета Северной Каролины в Чапел-Хилле и ИС РАН // http://www.hse.ru/rlms

4 За все рассматриваемые годы доля пар, в которых один из партнеров моложе 18 лет, составила лишь $0,18 \%$ от общего числа пар. Их исключение не влияет на общие результаты проведенного анализа.

5 Число удаленных наблюдений с неполной информацией составило менее $0,3 \%$ как среди состоящих, так и среди не состоящих в браке (см. ниже).
} 
структура населения по состоянию в браке и уровню образования складывается под воздействием разных процессов: первых браков, разводов, разрывов партнерских отношений, повторных браков, получения образования как до брака, так и в период нахождения в браке. Подобный подход - с использованием кросссекционных данных о текущем семейном положении - применяется во многих эмпирических исследованиях, посвященных образовательной избирательности браков [Kalmijn 2013; Eika et al. 2019].

Дескриптивные статистики по ключевым переменным представлены в таблице 1. Мы видим, что за 1995-2015 гг. средний возраст состоящих в браке увеличился на 4 года - с 44 до 48 лет, при этом средняя разница в возрасте между мужьями и женами сохранилась в пределах 2,0-2,2 лет. Как и следовало ожидать, среди населения, не состоящего в браке, больше молодежи и лиц старшего возраста, особенно женщин.

\section{Таблица 1. Описание выборки}

\begin{tabular}{|c|c|c|c|c|c|c|}
\hline & \multicolumn{3}{|c|}{ Супружеские пары } & \multicolumn{3}{|c|}{ Не состоящие в браке } \\
\hline & 1995 & 2005 & 2015 & 1995 & 2005 & 2015 \\
\hline \multicolumn{7}{|c|}{ Состоят в браке, \% } \\
\hline Зарегистрированный брак & н.д. & $\begin{array}{c}85,1^{*} \\
(0,6)\end{array}$ & $\begin{array}{l}83,8^{*} \\
(0,5)\end{array}$ & - & - & - \\
\hline Незарегистрированный брак & н.д. & $\begin{array}{l}13,5 \\
(0,6)\end{array}$ & $\begin{array}{l}15,6 \\
(0,5)\end{array}$ & - & - & - \\
\hline \multicolumn{7}{|c|}{ Не состоят в браке, \% } \\
\hline Никогда не состояли в браке & - & - & - & $\begin{array}{l}33,7 \\
(0,9)\end{array}$ & $\begin{array}{l}39,5 \\
(0,9)\end{array}$ & $\begin{array}{l}38,3 \\
(0,8)\end{array}$ \\
\hline Разведены и в браке не состоят & - & - & - & $\begin{array}{l}21,2 \\
(0,8)\end{array}$ & $\begin{array}{l}20,0 \\
(0,8)\end{array}$ & $\begin{array}{l}20,3 \\
(0,6)\end{array}$ \\
\hline Вдовцы (вдовы) & - & - & - & $\begin{array}{l}39,5 \\
(1,0)\end{array}$ & $\begin{array}{l}35,0 \\
(0,9)\end{array}$ & $\begin{array}{l}36,2 \\
(0,8)\end{array}$ \\
\hline \multicolumn{7}{|c|}{ Средний возраст, лет } \\
\hline мужья/мужчины & $\begin{array}{l}45,4 \\
(0,2)\end{array}$ & $\begin{array}{l}48,2 \\
(0,3)\end{array}$ & $\begin{array}{l}49,5 \\
(0,3)\end{array}$ & $\begin{array}{l}35,8 \\
(0,7)\end{array}$ & $\begin{array}{l}33,9 \\
(0,6)\end{array}$ & $\begin{array}{l}36,1 \\
(0,5)\end{array}$ \\
\hline жены/женщины & $\begin{array}{l}43,4 \\
(0,3)\end{array}$ & $\begin{array}{l}46,2 \\
(0,3)\end{array}$ & $\begin{array}{l}47,3 \\
(0,3)\end{array}$ & $\begin{array}{l}52,9 \\
(0,5)\end{array}$ & $\begin{array}{l}51,9 \\
(0,5)\end{array}$ & $\begin{array}{l}55,0 \\
(0,4)\end{array}$ \\
\hline $\begin{array}{l}\text { Средняя разница в возрасте } \\
\text { между мужьями и женами, лет }\end{array}$ & $\begin{array}{l}2,0 \\
(0,1)\end{array}$ & $\begin{array}{c}2,0 \\
(0,1)\end{array}$ & $\begin{array}{c}2,2 \\
(0,1)\end{array}$ & - & - & - \\
\hline Количество наблюдений & 5202 & 3826 & 5920 & 2518 & 2717 & 4047 \\
\hline
\end{tabular}

* Сумма не сходится к 100\% из-за различий в ответах партнеров; в скобках - стандартные ошибки. 
За рассматриваемые 20 лет произошла существенная трансформация образовательной структуры населения (рисунок 1). Как среди женщин, так и среди мужчин наблюдалась четкая тенденция роста доли лиц с высшим образованием, при этом среди женщин доля лиц с высшим образованием увеличилась в 1995-2015 гг. почти на 13 п. п. - с 15 до 28\%; среди мужчин соответствующий прирост составил 6 п. п. - с 16 до 22\%. Если в середине 1990-х гг. доли мужчин и женщин с высшим образованием были примерно равны, то к концу рассматриваемого периода появляется явно выраженная гендерная асимметрия в пользу женщин 6 . Как среди мужчин, так и среди женщин увеличение доли обладателей вузовских дипломов происходило за счет сокращения доли лиц с образованием не выше среднего.

Образовательные тренды населения, состоящего и не состоящего в браке, оказались очень схожими. В силу возрастных различий одинокие респонденты имели более низкий уровень образования, однако с течением времени различия между состоящими и не состоящими в браке постепенно сокращались прежде всего за счет ухода старших когорт с очень низким уровнем образования. Как среди одиноких, так и среди состоящих в браке росла доля обладателей вузовских дипломов, и среди женщин быстрее, чем среди мужчин.

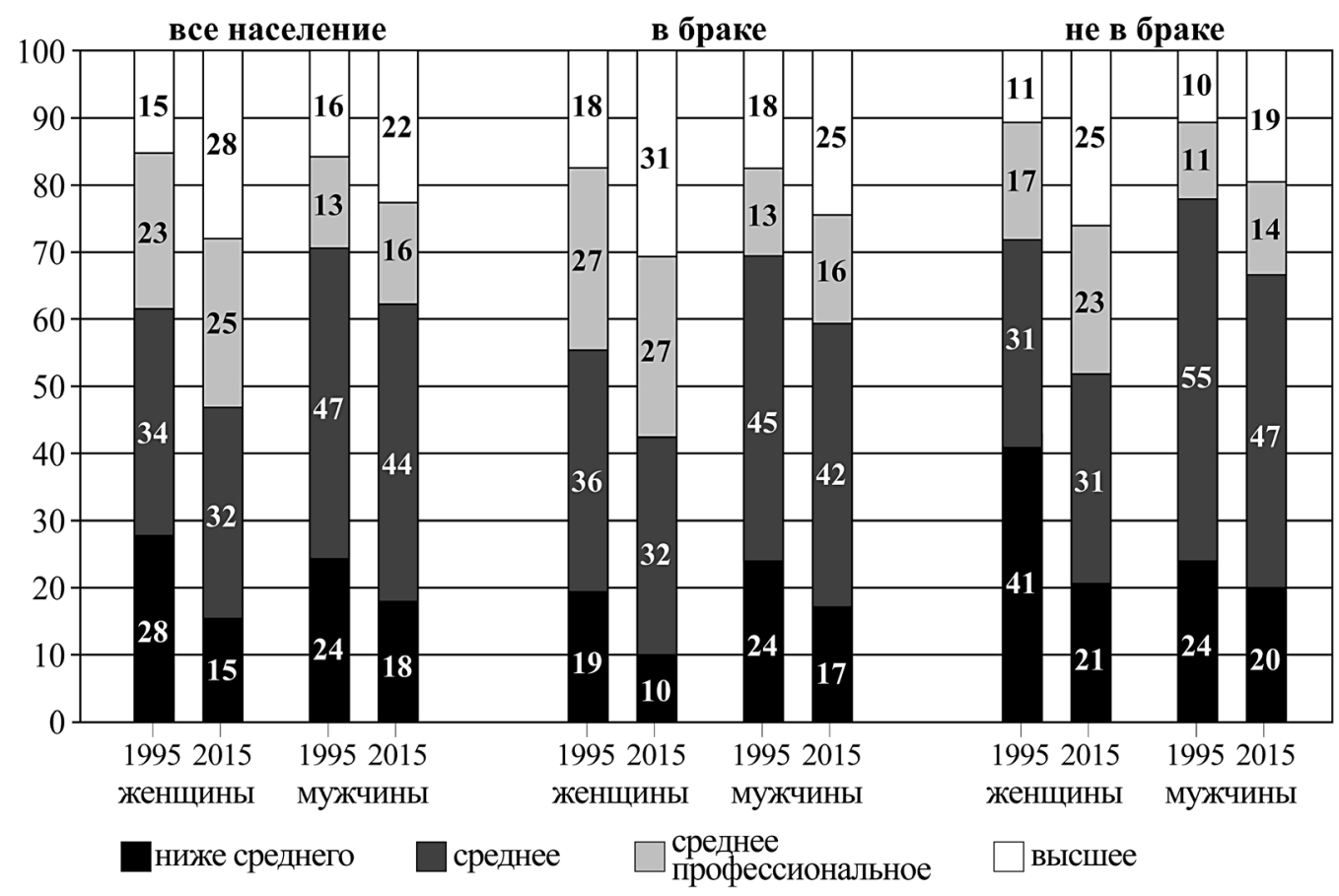

Рисунок 1. Распределение населения по уровню образования

\footnotetext{
6 Данные переписи населения несколько отличаются от выборки РМЭЗ ВШЭ в оценках охвата населения высшим и особенно средним профессиональным образованием, но они также указывают на резкое сокращение доли тех, чье образование ниже полного среднего, и на опережающий рост уровня образованности среди женщин.
} 


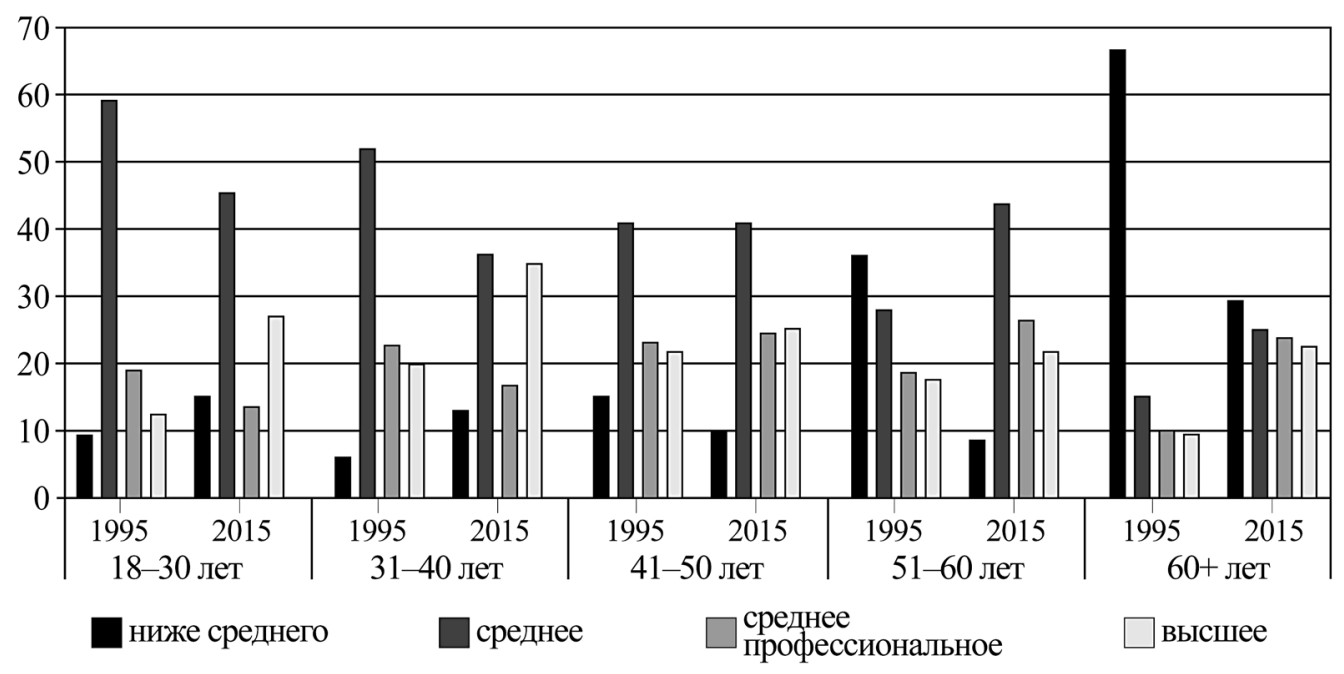

Рисунок 2. Распределение населения по уровню образования и возрасту

Рост образованности коснулся не только молодых групп (рисунок 2) - охват высшим образованием увеличился во всех возрастных группах. В возрастах старше 50 лет лица с неполным средним образованием постепенно замещались обладателями среднего и среднего профессионального образования. Фактически мы наблюдаем последствия не одного, а двух образовательных бумов - послевоенного бума среднего и среднего профессионального образования и бума высшего образования, пришедшегося на конец 1990-х - 2000-е гг.

\section{Как изменялся брачный статус населения?}

Усиление гендерной асимметрии в образовании в пользу женщин, отмеченное в предыдущем разделе, могло иметь далеко идущие последствия для брачных рынков и стратегий формирования семьи. Возможными последствиями являются рост доли мужчин и женщин, не состоящих в браке, и увеличение доли браков, в которых жены более образованны, чем их мужья.

Сначала обратимся к изменениям в доле населения, состоящего в браке. Данные РМЭЗ ВШЭ показывают заметные сдвиги в этом показателе за последние 20 лет (таблица 2). В первой половине рассматриваемого периода происходило снижение доли состоящих в браке для обоих полов, в 2005-2015 гг. сокращение сменилось небольшим ростом, прежде всего за счет многочисленных когорт, родившихся в конце 1980-х гг. (нельзя исключать, что наблюдаемый рост отчасти является статистическим артефактом, связанным с ремонтом выборки РМЭЗ ВШЭ в 2010 г.). В любом случае увеличение доли состоящих в браке во второй половине рассматриваемого периода, если оно имело место, оказалось недостаточным для того, чтобы компенсировать падение показателей в 1995-2005 гг. 
Таблица 2. Доля населения, состоящего в браке, по образовательным группам, \%

\begin{tabular}{|c|c|c|c|c|c|c|}
\hline Уровень образования & 1995 & 2000 & 2005 & 2010 & 2015 & $\begin{array}{l}\text { Изменение } \\
\text { 1995-2015 }\end{array}$ \\
\hline \multicolumn{7}{|c|}{ Женщины } \\
\hline Все - фактически & $\begin{array}{l}59,3 \\
(0,7)\end{array}$ & $\begin{array}{l}54,7 \\
(0,8)\end{array}$ & $\begin{array}{l}50,5 \\
(0,8)\end{array}$ & $\begin{array}{l}51,7 \\
(0,6)\end{array}$ & $\begin{array}{l}51,2 \\
(0,7)\end{array}$ & $\begin{array}{l}-8,1 \\
(1,0)\end{array}$ \\
\hline $\begin{array}{l}\text { Все - расчетно, при сохранении } \\
\text { образовательной структуры } 1995 \text { г. }\end{array}$ & $\begin{array}{l}59,3 \\
(0,7)\end{array}$ & $\begin{array}{l}54,2 \\
(1,0)\end{array}$ & $\begin{array}{l}49,2 \\
(1,1)\end{array}$ & $\begin{array}{l}49,6 \\
(1,3)\end{array}$ & $\begin{array}{l}48,3 \\
(1,6)\end{array}$ & $\begin{array}{l}-11,0 \\
(1,6)\end{array}$ \\
\hline Ниже среднего & $\begin{array}{l}40,5 \\
(1,4)\end{array}$ & $\begin{array}{l}39,8 \\
(1,6)\end{array}$ & $\begin{array}{l}33,0 \\
(1,6)\end{array}$ & $\begin{array}{l}35,5 \\
(1,3)\end{array}$ & $\begin{array}{l}33,9 \\
(1,6)\end{array}$ & $\begin{array}{l}-6,6 \\
(2,1)\end{array}$ \\
\hline Среднее & $\begin{array}{l}63,3 \\
(1,2)\end{array}$ & $\begin{array}{l}56,6 \\
(1,3)\end{array}$ & $\begin{array}{l}53,5 \\
(1,4)\end{array}$ & $\begin{array}{l}54,1 \\
(1,0)\end{array}$ & $\begin{array}{l}51,9 \\
(1,2)\end{array}$ & $\begin{array}{l}-11,4 \\
(1,7)\end{array}$ \\
\hline Среднее профессиональное & $\begin{array}{l}69,6 \\
(1,5)\end{array}$ & $\begin{array}{l}63,7 \\
(1,6)\end{array}$ & $\begin{array}{l}59,4 \\
(1,7)\end{array}$ & $\begin{array}{l}56,0 \\
(1,1)\end{array}$ & $\begin{array}{l}55,0 \\
(1,3)\end{array}$ & $\begin{array}{l}-14,6 \\
(2,0)\end{array}$ \\
\hline Высшее & $\begin{array}{l}69,3 \\
(1,8)\end{array}$ & $\begin{array}{l}61,3 \\
(1,9)\end{array}$ & $\begin{array}{l}54,1 \\
(1,8)\end{array}$ & $\begin{array}{l}56,0 \\
(1,1)\end{array}$ & $\begin{array}{l}56,4 \\
(1,2)\end{array}$ & $\begin{array}{l}-12,8 \\
(2,2)\end{array}$ \\
\hline \multicolumn{7}{|c|}{ Мужчины } \\
\hline Все - фактически & $\begin{array}{l}78,1 \\
(0,7)\end{array}$ & $\begin{array}{l}74,4 \\
(0,8)\end{array}$ & $\begin{array}{l}69,5 \\
(0,9)\end{array}$ & $\begin{array}{l}71,2 \\
(0,6)\end{array}$ & $\begin{array}{l}70,7 \\
(0,7)\end{array}$ & $\begin{array}{l}-7,4 \\
(1,0)\end{array}$ \\
\hline $\begin{array}{l}\text { Все - расчетно, при сохранении } \\
\text { образовательной структуры } 1995 \text { г. }\end{array}$ & $\begin{array}{l}78,1 \\
(0,8)\end{array}$ & $\begin{array}{l}74,4 \\
(1,0)\end{array}$ & $\begin{array}{l}69,5 \\
(1,2)\end{array}$ & $\begin{array}{l}70,6 \\
(1,4)\end{array}$ & $\begin{array}{l}69,9 \\
(1,6)\end{array}$ & $\begin{array}{l}-8,1 \\
(1,7)\end{array}$ \\
\hline Ниже среднего & $\begin{array}{l}77,8 \\
(1,5)\end{array}$ & $\begin{array}{l}74,4 \\
(1,7)\end{array}$ & $\begin{array}{l}69,7 \\
(2,0)\end{array}$ & $\begin{array}{l}69,0 \\
(1,4)\end{array}$ & $\begin{array}{l}66,8 \\
(1,7)\end{array}$ & $\begin{array}{l}-10,9 \\
(2,3)\end{array}$ \\
\hline Среднее & $\begin{array}{l}74,4 \\
(1,1)\end{array}$ & $\begin{array}{l}69,4 \\
(1,3)\end{array}$ & $\begin{array}{l}65,6 \\
(1,3)\end{array}$ & $\begin{array}{l}68,3 \\
(0,9)\end{array}$ & $\begin{array}{l}68,1 \\
(1,1)\end{array}$ & $\begin{array}{l}-6,3 \\
(1,6)\end{array}$ \\
\hline Среднее профессиональное & $\begin{array}{l}80,7 \\
(1,9)\end{array}$ & $\begin{array}{l}83,3 \\
(1,9)\end{array}$ & $\begin{array}{l}76,7 \\
(2,2)\end{array}$ & $\begin{array}{l}75,3 \\
(1,4)\end{array}$ & $\begin{array}{l}73,6 \\
(1,7)\end{array}$ & $\begin{array}{l}-7,1 \\
(2,6)\end{array}$ \\
\hline Высшее & $\begin{array}{l}87,1 \\
(1,4)\end{array}$ & $\begin{array}{l}81,7 \\
(1,8)\end{array}$ & $\begin{array}{l}74,7 \\
(2,0)\end{array}$ & $\begin{array}{l}76,0 \\
(1,3)\end{array}$ & $\begin{array}{l}76,8 \\
(1,4)\end{array}$ & $\begin{array}{l}-10,3 \\
(2,0)\end{array}$ \\
\hline
\end{tabular}

Примечание: в скобках - стандартные ошибки. Для расчетных значений стандартные ошибки получены методом бутстрапа.

В силу различий в возрастной структуре, продолжительности жизни и вероятности вступления в повторный брак во все годы доля состоящих в браке была значительно ниже среди женщин, чем среди мужчин. Мужчины в среднем позже вступали в первый брак, но реже оставались одни после развода/разрыва или смерти жены. Первый раз женщины выходили замуж в более раннем возрасте, но чаще оставались одни в старшем возрасте. Несмотря на значительные различия 
в уровне показателя, снижение доли состоящих в браке наблюдалось у обоих полов и происходило схожими темпами ${ }^{7}$.

Таблица 2 иллюстрирует динамику брачного статуса по полу и уровню образования. Уменьшение доли состоящих в браке охватило все образовательные группы, но с сильной гендерной спецификой. Среди женщин образование слабо влияло на вероятность вступления в брак; процент женщин, состоящих в браке, был ощутимо ниже лишь в наименее образованной (очень малочисленной) группе. Для всех остальных образовательных групп доля женщин, состоящих в браке, оказалась примерно одинаковой. Изменения в значении показателя за 1995-2015 гг. также схожи для всех групп женщин, кроме наименее образованных: процент состоящих в браке сократился на $11-15$ п. п. - с 60-70\% в 1995 г. до 50-55\% в 2015 г. Среди женщин с образованием ниже среднего снижение доли состоящих в браке было не столь значительным, но разрыв с более образованными группами остается все же большим.

Другая картина наблюдается среди мужчин: в крайних образовательных группах произошло наиболее интенсивное сокращение доли состоящих в браке. Мужчины с низким уровнем образования и низким уровнем доходов в последние годы теряли шансы на брачном рынке. Среди мужчин с образованием ниже среднего доля состоящих в браке снизилась за 1995-2015 гг. на 11 п. п. - с 78 до 67\%. В конце периода столь же низок был процент состоящих в браке и для мужчин, имеющих полное среднее образование, однако для этой группы сокращение показателя по сравнению с 1995 г. оказалось достаточно умеренным. Высшее образование, похоже, давало мужчинам серьезные преимущества на брачном рынке: у мужчин с высшим образованием шансы состоять в браке заметно (на 3-10 п. п.) выше, чем у менее образованных групп; образованные мужчины более привлекательны с точки зрения зарплатного потенциала и пользуются высоким спросом на брачном рынке, но вместе с тем имеют возможность дольше искать подходящую пару.

Для того, чтобы оценить вклад трендов в сфере образования в изменение распределения населения по брачному статусу, мы рассчитали, какой была бы доля состоящих в браке, если бы образовательная структура во все годы оставалась такой же, как в 1995 г. Для расчета этого показателя мы перемножили фактические доли состоящих в браке в каждой образовательной группе (отдельно для мужчин и женщин) на доли соответствующих уровней образования в 1995 г. и затем сложили все полученные значения, получив средневзвешенное значение. Результаты представлены в таблище 2. Здесь мы видим, что и у мужчин, и у женщин изменения в образовательной структуре тормозили снижение доли состоящих в браке, причем у женщин заметно сильнее, чем у мужчин. Если бы образовательная структура осталась неизменной, то доля состоящих в браке была бы еще ниже - на 2,9 п. п. в 2015 г. у женщин и на 0,8 п. п. у мужчин. Расхождение между фактическим и расчетным значениями происходит из-за того, что в фактической образовательной структуре увеличился процент более образованных групп, в которых

\footnotetext{
7 Оценки по РМЭЗ ВШЭ в целом согласуются с данными переписей. Несмотря на то, что оценки доли состоящих в браке в данных переписи несколько ниже, общие тренды совпадают: резкое снижение доли состоящих в браке произошло именно в 1990-е гг. Завышение оценки доли состоящих в браке в РМЭЗ ВШЭ может быть связано с тем, что обследование не охватывает общежития и институциональные домохозяйства, где проживают преимущественно люди, не состоящие в браке.
} 
выше доля состоящих в браке. Из сказанного следует важный вывод о том, что доля состоящих в браке снижалась не из-за изменений в образовательной структуре населения. Это не означает, что образование не играло никакой роли: рост отдачи от образования и опережающий рост уровня образования среди женщин могли способствовать снижению экономической ценности брака для разных образовательных групп. Однако для изучения этих аспектов воздействия образования на брак необходим более сложный эконометрический анализ вкупе с иным инструментарием социологического и демографического характера.
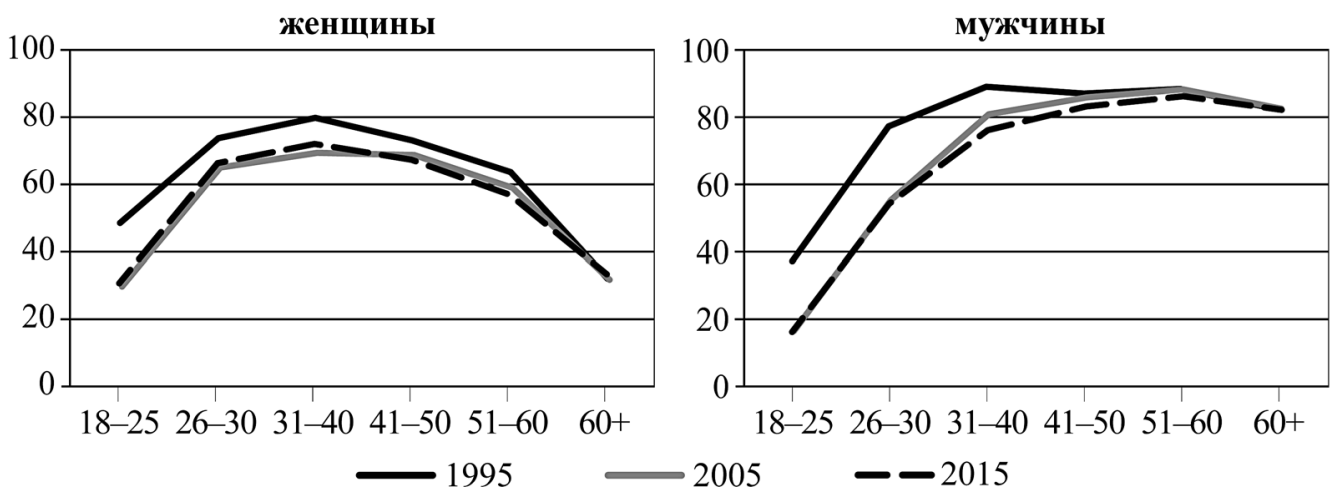

Рисунок 3. Доля состоящих в браке или партнерском союзе по возрастным группам, \%

Логично ожидать наибольшего динамизма в эволюции брачных паттернов среди молодежи. На рисунке 3 представлены изменения в брачном статусе в разрезе возрастных групп. У женщин зависимость между возрастом и вероятностью состоять в браке имеет форму перевернутой буквы U, у мужчин - перевернутой буквы L, т. е. без снижения в старших возрастах. Из рисунка 3 видно, что резкое сокращение доли состоящих в браке произошло в период с 1995 по 2015 г. и в той или иной степени затронуло все группы в возрастах вплоть до 50 лет у мужчин и вплоть до 60 лет у женщин. Изменения особенно ярко проявились в поведении молодежи: среди молодых мужчин в возрасте 18-25 лет процент состоящих в браке сократился на 20 п. п., а среди молодых женщин - на 18 п. п. Среди мужчин это снижение было значительным и в следующих возрастных группах (26-30 лет и 31-40 лет), затем эффект быстро затухает. Среди женщин от 26 до 60 лет доля состоящих в браке сократилась примерно на одну и ту же величину - около 7 п. п. Таким образом, уменьшение количества состоящих в браке нельзя полностью отнести на отсрочку вступления в брак в связи с получением образования и выходом на рынок труда: к более старшим возрастам полного восстановления показателя до уровня середины 1990-х гг. не происходило.

Как среди мужчин, так и среди женщин мы видим снижение шансов малообразованных групп на вступление в брак/сохранение брака, что отчасти связано с естественным старением этой группы. Получение высшего образования оказы- 
вает более сильное позитивное влияние на брачные шансы мужчин, чем женщин; для женщин оно играет, скорее, нейтральную роль. Тренды в образовательной структуре населения тормозили снижение доли состоящих в браке, причем у женщин более выраженно, чем у мужчин, при этом увеличение доли не состоящих в браке не было прямым следствием изменений в образовательной структуре.

\section{Изменения в избирательности браков по уровню образования}

В литературе было предложено множество различных методов измерения избирательности браков, но в данной статье мы будем использовать самые простые и популярные из них - это показатели гомогамии, гипогамии и гипергамии. Образовательная гомогамия характеризует долю пар, в которых супруги имеют одинаковый уровень образования; гипогамия описывает брак женщины с мужчиной, имеющим более низкий уровень образования; и гипергамия - брак женщины с мужчиной, имеющим более высокий уровень образования. Все эти показатели рассчитываются на основе простых таблиц сопряженности, где уровень образования мужей (столбец) соотносится с уровнем образования жен (строки). Сумма элементов главной диагонали дает показатели гомогамии, ниже главной диагонали - гипогамии, выше главной диагонали - гипергамии.

Основным недостатком семейства показателей гомогамии является то, что при анализе их динамики не учитываются изменения в образовательной структуре населения. Поэтому изменения в таблицах сопряженности скорее отражают сдвиги в структуре населения, а не в предпочтениях индивидов относительно брака с обладателями определенного уровня образования. Это затруднение можно преодолеть, если стандартизировать таблицы сопряженности по отношению к образовательной структуре населения в базовом году. В настоящей работе процедура стандартизации реализована в алгоритме Синхорна-Кноппа [Sinkhorn, Knopp 1967]. Она позволяет получить для любого периода контрафактические значения показателей гомогамии, которые наблюдались бы при условии, что распределения мужей и жен по уровню образования остались бы на уровне некоторого базового года, и математически представляет собой итерационный процесс перевзвешивания элементов исходной таблицы сопряженности ${ }^{8}$.

Рисунок 4 отражает динамику простых и скорректированных показателей гомогамии. В соответствии с простыми показателями, все больше женщин состояли в браках, в которых мужья имели более низкий уровень образования (гипогамия): представленность таких пар увеличилась примерно на 5,5 п. п. - с 31,1\% в 1995 г. до $36,6 \%$ в 2015 г. Распространение гипогамных браков происходило прежде всего за счет сокращения доли пар, в которых партнеры имели одинаковое образование (гомогамных браков), доля которых снизилась на 4,7 п. п. - с 50,8 до 46,1\%. Вместе

\footnotetext{
8 В демографии и социологии более популярным методом исследования избирательности браков является логлинейный анализ (например, [Schwartz, Mare 2005]). Однако при его использовании результаты зависят от выбора спецификации модели. В данной работе для стандартизации таблиц сопряженности применяется алгоритм Синхорна-Кноппа. Это популярный в машинном обучении численный метод, не требующий предпосылок в функциональной форме; в контексте образовательной гомогамии он использовался ранее в [Greenwood et al. 2014].
} 
с тем гомогамные браки по-прежнему остаются самым распространенным видом брака, хотя их позиции за последние 20 лет пошатнулись. Сценарий традиционалистской семьи, где муж более образован, чем жена (гипергамия), становится наименее распространенной моделью брака; уже в середине 1990-х гг. гипогамия оказалась более «популярной», чем гипергамия: в 1995 г. доля гипергамных пар составляла 18,2\%, и Россия в 1990-е гг. была одной из стран с самым низким уровнем гипергамии. К 2015 г. эта доля изменилась незначительно, составив 17,4\%.

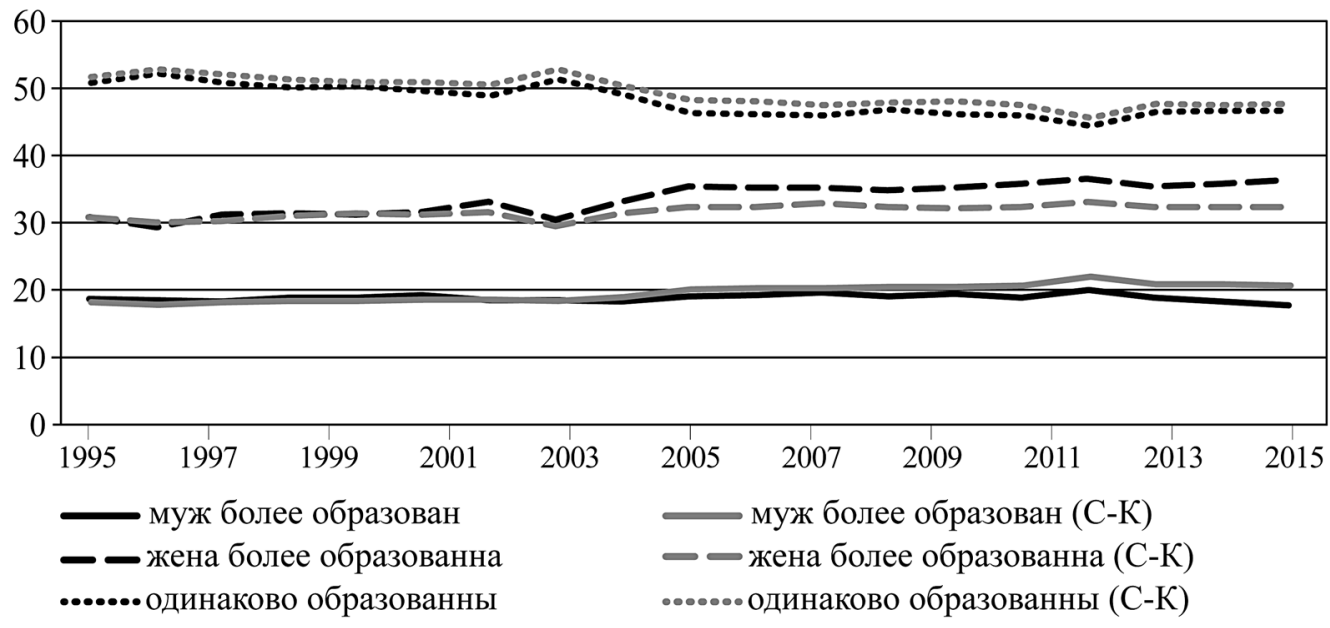

Рисунок 4. Соотношение уровней образования мужей и жен, \% от общего числа супружеских пар

Примечание: расчеты приведены на основании таблиц сопряженности для 1995 и 2015 гг. (рисунок 5).

При расчетах по алгоритму Синхорна-Кноппа в качестве базы была взята образовательная структура 1995 г. Стандартизированные таблицы показывают, каким оказался бы состав семей по уровню образования супругов, если бы образовательная структура была «заморожена» на уровне 1995 г., а вероятность состоять в браке с обладателем определенного уровня образования менялась бы в соответствии с фактическими значениями. Согласно полученным оценкам, доля пар, в которых партнеры имеют одинаковое образование, снижалась, но не так сильно, как в нестандартизированных таблицах. В 2015 г. скорректированный показатель гомогамии был на 4,1 п. п. ниже по сравнению с 1995 г. (для сравнения: с -4,7 п. П. до стандартизации). Довольно неожиданно увеличилось на 2,6 п. п. количество пар, где муж более образован, чем жена. Этот результат не согласуется с тем, что демонстрировали простые показатели гипергамии, которые указывали на сокращение представленности таких союзов. Доля гипогамных браков выросла всего на 1,5 п. п., а не на 5,5 п. п., как при использовании нескорректированных показателей.

Таким образом, учет тенденций в сфере образования позволяет поправить наши выводы, выделив вклад изменений в образовательной структуре и изменений 
в предпочтениях (склонности к браку с обладателем определенного уровня образования). Декомпозиция на две составляющие производится следующим образом:

$$
\Phi а к m_{2015}-\Phi а к m_{1995}=\underbrace{\Phi a \kappa m_{2015}-C K_{2015}}_{\begin{array}{c}
\text { Изменения в образовательной } \\
\text { структуре }
\end{array}}+\underbrace{C K_{2015}-\Phi а к m_{1995}}_{\text {Изменения в предпочтениях }}
$$

Результаты декомпозиции показывают, что увеличение доли пар, в которых муж имеет более низкий уровень образования, в фактических данных на три четверти объясняется изменениями в образовательной структуре населения и лишь на одну четверть - сдвигом в фактической избирательности браков. На самом деле склонность индивидов к принятию гипогамных браков менялась медленнее, чем если судить о них по фактическим трендам. Вместе с тем мы видим признаки возможной архаизации брачных паттернов, что отражается в заметном росте гипергамии. В фактических данных эта тенденция маскировалась сокращением доли малообразованных групп, но если исключить влияние этого фактора, то в 2015 г. больше женщин состояли в браке с более образованным мужем, чем в 1995 г. При этом доля «равных» браков сокращалась, т. е. происходила медленная поляризация в структуре семей по уровню образования.

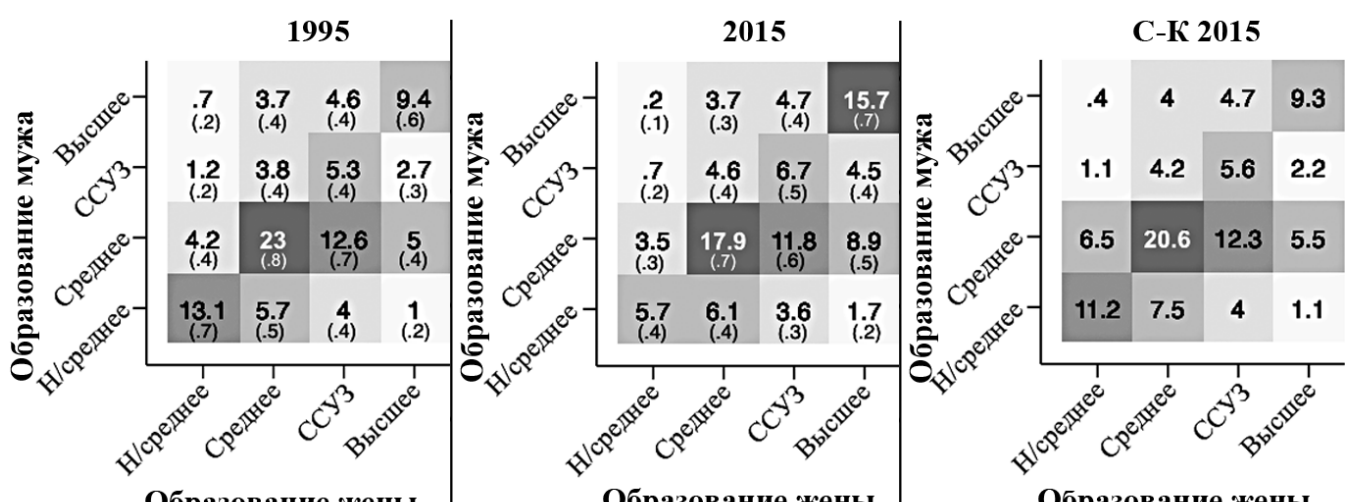

Образование жены

Образование жены

Образование жены

Рисунок 5. Состав семей по уровню образования мужей и жен, \% от общего числа супружеских пар

Примечание: левая и центральная таблицы построены по фактическим данным; правая таблица для 2015 г. - по методу Синхорна-Кноппа; ячейки с большей долей супружеских пар закрашены более темным цветом; в скобках - стандартные ошибки.

Рисунок 5 позволяет понять, за счет каких комбинаций уровней образования супругов происходили указанные изменения. Левая и центральная таблицы на $p u-$ сунке 5 построены по фактическим данным 1995 и 2015 гг. соответственно; правая таблица рассчитана по алгоритму Синхорна-Кноппа наложением образовательной 
структуры 1995 г. на структуру образовательно-брачных паттернов 2015 г. Ячейки с большей долей супружеских пар закрашены более темным цветом. Так, в 2015 г. самой распространенной была комбинация, когда оба супруга имеют среднее образование (18\% от общего числа супружеских пар), на втором месте - пары, где оба супруга имеют высшее образование (16\%), на третьем месте - пары, где у мужа - среднее образование, у жены - среднее профессиональное (12\%). При этом в 1995 г. также чаще всего встречались пары, в которых оба супруга имели среднее образование, но второе место по частоте занимали пары, в которых у обоих супругов - образование ниже среднего, а третье место, как и в 2015 г., принадлежало парам, в которых муж имеет среднее образование, жена - среднее профессиональное. Семьи, где у обоих супругов высшее образование, даже не входили в 1995 г. в первую тройку.

Мы видим, что снижение гомогамии в фактических данных было обусловлено сокращением доли пар, в которых оба супруга имеют неполное среднее или среднее образование. При этом увеличилась доля пар, в которых у обоих супругов высшее образование либо среднее профессиональное образование. Однако приросты в двух последних группах не смогли компенсировать падение в двух первых. Расчеты по методу Синхорна-Кноппа показывают, что почти весь прирост доли пар, в которых оба супруга имеют высшее или среднее профессиональное образование, произошел за счет сдвигов в образовательной структуре - с ростом охвата высшим образованием. А вероятность того, что женщина, например, с высшим образованием состоит в браке с таким же высокообразованным мужчиной, осталась примерно такой же, какой была в середине 1990-х гг., т. е. ни среди мужчин, ни среди женщин с высшим образованием не наблюдалось увеличения склонности к браку с обладателем такого же уровня образования. Снижение гомогамии среди менее образованных групп также на две трети объясняется изменениями в образовательной структуре - сокращением доли малообразованных групп населения. Но среди малообразованных групп наблюдалось и реальное снижение склонности к браку с «себе подобными».

Рост доли браков, в которых жена образованнее мужа, в фактических данных наблюдался за счет увеличения доли женщин с высшим образованием, состоящих в браке с мужчинами с более низким, прежде всего средним, уровнем образования. Стандартизация опять же указывает на то, что этот процесс почти целиком был связан с опережающим ростом охвата женщин высшим образованием, и реального изменения в склонности женщин с высшим образованием к гипогамным бракам не происходило. При этом применение метода Синхорна-Кноппа позволяет выделить неочевидную группу, в которой наблюдалось увеличение склонности к гипогамии - это пары, в которых жена со средним образованием, а муж с образованием ниже среднего.

Касательно гипергамии. Как мы говорили выше, в фактических данных ее уровень почти не менялся, но значительно вырос после стандартизации. Весь рост также определялся одним типом пар: муж имеет среднее образование, жена не имеет среднего образования.

Общий вывод из анализа таблиц сопряженности можно сформулировать следующим образом: анализируя фактические тренды, мы фиксируем увеличение доли гипогамных браков за счет гомогамных, при этом динамика сильно различается в зависимости от уровня образования. Среди обладателей высоких уровней 
образования росло количество и гипо-, и гомогамных браков; среди обладателей низкого уровня образования резко сократился процент гомогамных браков, что и определило общую тенденцию снижения доли таких браков. Основным драйвером изменений в образовательно-брачных паттернах явился мощный рост образованности населения. Однако предпочтения относительно образовательных характеристик супруга за 20 лет почти не изменились для тех, кто обладал высоким уровнем образования, и наоборот, среди тех, у кого был низкий уровень образования, наблюдалось смещение предпочтений за счет размывания границ между неполным и полным средним образованием.

Расчеты по отдельным возрастным группам показывают, что в фактических данных гомогамия снизилась во всех возрастных группах, но сильнее всего среди самых молодых (-6,5 п. п.) и самых пожилых (-13,4 п. п.) (таблица 3). Для выделения возрастных групп использовался возраст жены. Во всех возрастных группах гомогамия сохраняла позиции доминирующего типа брака, однако в группе 41-50 лет доли гомо- и гипогамных браков уже практически сравнялись, при этом как в более молодых, так и в более старших возрастах разрыв между гомо- и гипогамными браками был выше. Впрочем, подобная вариация по возрастам наблюдалась и в 1995 г., и даже с большей амплитудой. Разрыв в молодых возрастах может быть отчасти связан с более поздним вступлением в брак тех, кто имеет высшее образование; в старших возрастах большую роль играет смена поколений. Во всех возрастных группах было отмечено увеличение доли гипогамных браков, при этом минимальный прирост произошел среди молодежи $(+2,2$ п. п.), и далее он увеличивался с каждой следующей возрастной группой, достигнув $+13,8$ п. п. среди пар старше 60 лет. Что касается процента гипергамных браков, то он вырос только в молодой группе (+4,3 п. п.) и снизился во всех остальных группах; сильнее всего снижение доли гипергамных браков затронуло браки 40-60-летних.

Таблица 3. Соотношение уровней образования мужей и жен, в процентах от общего числа супружеских пар в каждой возрастной группе

\begin{tabular}{|l|c|c|c|c|c|c|}
\hline \multirow{2}{*}{ Возраст } & \multicolumn{2}{|c|}{$\begin{array}{c}\text { Образование мужа выше } \\
\text { (гипергамия) }\end{array}$} & \multicolumn{2}{|c|}{$\begin{array}{c}\text { Одинаковое образование } \\
\text { (гомогамия) }\end{array}$} & \multicolumn{2}{|c|}{$\begin{array}{c}\text { Образование жены выше } \\
\text { (гипогамия) }\end{array}$} \\
\cline { 2 - 7 } & $\mathbf{1 9 9 5}$ & $\mathbf{2 0 1 5}$ & $\mathbf{1 9 9 5}$ & $\mathbf{2 0 1 5}$ & $\mathbf{1 9 9 5}$ & $\mathbf{2 0 1 5}$ \\
\hline \multirow{2}{*}{$18-30$ лет } & $\begin{array}{c}16,0 \\
(1,6)\end{array}$ & $\begin{array}{c}20,3 \\
(1,9)\end{array}$ & $\begin{array}{c}51,9 \\
(2,1)\end{array}$ & $\begin{array}{c}45,4 \\
(2,3)\end{array}$ & $\begin{array}{c}32,1 \\
(2,0)\end{array}$ & $\begin{array}{c}34,3 \\
(2,2)\end{array}$ \\
\hline \multirow{2}{*}{$31-40$ лет } & 17,4 & 17,2 & 49,3 & 46,2 & 33,2 & 36,6 \\
& $(1,5)$ & $(1,5)$ & $(1,9)$ & $(1,9)$ & $(1,8)$ & $(1,9)$ \\
\hline \multirow{2}{*}{$41-50$ лет } & 20,0 & 17,3 & 43,2 & 42,4 & 36,8 & 40,3 \\
& $(1,7)$ & $(1,6)$ & $(2,1)$ & $(2,1)$ & $(2,0)$ & $(2,0)$ \\
\hline \multirow{2}{*}{$51-60$ лет } & 19,4 & 14,5 & 50,4 & 45,9 & 30,3 & 39,7 \\
& $(1,9)$ & $(1,4)$ & $(2,4)$ & $(2,0)$ & $(2,2)$ & $(2,0)$ \\
\hline \multirow{2}{*}{$60+$ лет } & 18,7 & 18,1 & 63,2 & 49,8 & 18,2 & 32,0 \\
& $(2,0)$ & $(1,5)$ & $(2,5)$ & $(1,9)$ & $(2,0)$ & $(1,8)$ \\
\hline
\end{tabular}

Примечание: в скобках - стандартные ошибки. 
Использование алгоритма Синхорна-Кноппа позволяет отследить вклад образовательных трендов в наблюдаемые изменения по возрастным группам. $P u$ сунок 6 построен на основе декомпозиции по формуле (1). Наблюдаемый рост гипогамии и снижение гомогамии практически полностью объясняются изменениями в образовательных структурах. Наиболее выражена роль образовательных трендов в старших возрастах (50 лет и старше), в которых вклад этого фактора превышает общую величину изменений в показателях гипо- и гомогамии. Это означает, что тренды в сфере образования перекрывали противоположную динамику фактора предпочтений. Так, для старших возрастных групп изменения в предпочтениях вносили отрицательный вклад в общую динамику гипогамии, т. е. в этих группах не произошло позитивных сдвигов по отношению к гипогамным бракам, но и в более молодых возрастах эти сдвиги, если и были, то минимальные.

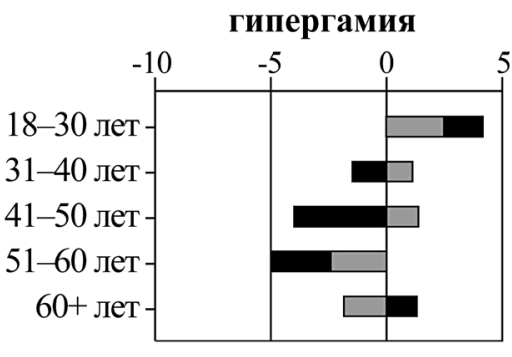

за счет предпочтений гомогамия

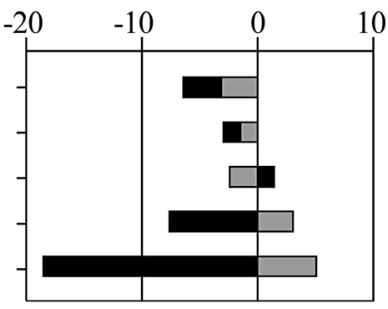

за счет образовательных сдвигов гипогамия

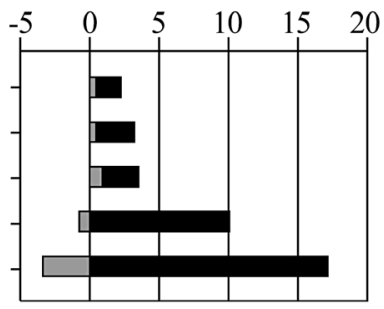

20

\section{Рисунок 6. Вклад образовательных сдвигов и предпочтений \\ в изменение показателей гомогамии}

Изменения в структуре образования объясняют и значительную часть снижения доли гомогамных браков. Во всех возрастных группах, кроме 41-50 лет, образовательные тренды действовали в сторону снижения гомогамии с наибольшей интенсивностью для старших возрастных групп. В группах 18-40 лет за снижение гомогамии в равной степени ответственны изменения в предпочтениях и образовательные тренды.

Отмеченная нами выше тенденция поляризации браков складывалась за счет молодых пар и пар среднего возраста: именно в этих возрастах мы наблюдаем одновременный рост предпочтений к гипогамии и гипергамии при сокращении предпочтений в отношении равных браков, при этом рост гипергамии выражен сильнее среди молодежи. Именно по этой причине пока рано говорить об архаизации брачных паттернов. Среди молодежи увеличение гипергамии может быть связано с более поздним вступлением в брак образованных групп населения, эта тенденция может элиминироваться по мере взросления когорт, но может свидетельствовать и об ухудшении образовательной структуры ранних браков. 


\section{Заключение}

Рост уровня образованности населения выступает мощным катализатором изменений в сфере брачно-семейных отношений. Масштабные технологические и социальные трансформации второй половины XX в. привели к резкому росту отдачи от образования, особенно для женщин, и способствовали изменению положения женщин в семье и обществе. В России на протяжении нескольких десятилетий средний уровень образования женщин опережает соответствующие показатели для мужчин, и разрыв продолжает увеличиваться. В данной работе мы исследовали, как образование влияет на брачно-партнерский статус, и как изменился за последние 20 лет состав российских семей по уровню образования супругов.

Наш анализ показывает, что взаимодействие демографических и образовательных тенденций не является простым и линейным: мы находим подтверждение прогнозов экономических теорий о снижении доли состоящих в браке по мере роста образованности женщин. Получение высокого уровня образования ведет к повышению доходов, что укрепляет привлекательность на брачном рынке, но одновременно снижает экономические стимулы для вступления в брак. Именно рост доли не состоящих в браке явился ключевой тенденцией 1995-2015 гг., которая касалась и мужчин, и женщин, но в большей степени женщин. При этом изменения в образовательной структуре населения замедляли сокращение доли состоящих в браке, поскольку в более образованных группах выше доля состоящих в браке. Представленность состоящих в браке сократилась практически во всех возрастах, поэтому это сокращение нельзя объяснить более поздним вступлением в брак в молодых когортах.

В структуре браков также происходили важные изменения. Несмотря на то, что образовательная гомогамия по-прежнему остается самым распространенным видом брака, в рассматриваемый период наблюдалось увеличение доли союзов, в которых мужья имеют более низкий уровень образования. Распространение таких браков происходило за счет сокращения доли пар, в которых партнеры имеют одинаковое образование. При этом на три четверти прирост гипогамии был обусловлен изменениями в образовательной структуре, и только на четверть - изменениями в предпочтениях относительно уровня образования супруга, т. е. смягчением гендерных стереотипов и принятием (обеими сторонами) браков, в которых женщина имеет более высокий уровень образования. Однако гендерные нормы в сфере брака адаптируются значительно медленнее, чем в сфере образования, и даже в молодых возрастах не наблюдалось существенного увеличения склонности к гипогамным бракам.

Изолировав влияние сдвигов в образовательной структуре, мы отметили еще одну тенденцию изменения в предпочтениях - это заметный рост выбора браков, в которых муж имеет более высокий уровень образования, что наиболее выражено среди молодых пар с низким уровнем образования. Мы не склонны интерпретировать данный результат как архаизацию брачных паттернов; возможно, этот тренд стал заметен на фоне откладывания вступления в брак с более образованными молодыми людьми. Тщательного исследования требует и анализ других каналов влияния образования на брачно-партнерский статус и образовательную избирательность браков - через повышение отдачи от образования, особенности региональных образовательных структур и брачных рынков. 


\section{Литература}

Бессуднов А.Р., Куракин Д.Ю., Малик В.М. (2017) Как возник и что скрывает миф о всеобщем высшем образовании // Вопросы образования. № 3. С. 83-109.

Волков А.Г. (2014) Избранные демографические труды: сборник научных статей. М.: ВШЭ. Гурко Е.М. (2006) Представления студенческой молодежи о браке // Гурко Е.М. (ред.) Актуальные проблемы семей в России. М.: ИС РАН. С. 200-210.

Гурко Т.А., Мамиконян М.С. (2018) Установки студентов в брачно-семейной сфере и отношениях между полами // Вестник Института социологии. Т. 9. №. 4. С. 192-226.

Захаров С.В. (2007) Трансформация брачно-партнерских отношений в России: «золотой век» традиционного брака близится к закату? // Малева Т.М., Синявская О.В. (ред.) Родители и дети, мужчины и женщины в семье и обществе. Вып. 1. М.: НИСП. С. $75-126$.

Зинченко Д.И., Лукьянова А.Л. (2018) Ассортативность браков по образованию и неравенство доходов // Экономический журнал ВШЭ. Т. 22. № 2. С. 169-196.

Рощина Я.М., Рощин С.Ю. (2008) Брачный рынок в России: выбор партнера и факторы успеха // Математическое моделирование. № 4. С. 21-37.

Сороко Е.Л. (2014) Этнически смешанные супружеские пары в Российской Федерации // Демографическое обозрение № 4. С. 96-123.

Autor D., Dorn D., Hanson G. (2019) When Work Disappears: Manufacturing Decline and the Falling Marriage Market Value of Young Men // American Economic Review: Insights, vol. 1, no 2, pp. 161-178.

Becker G. (1973) A Theory of Marriage // Journal of Political Economy, vol. 81, no 4, pp. 813-846.

Blossfeld H. (2009) Educational Assortative Marriage in Comparative Perspective // Annual Review of Sociology, vol. 35, pp. 513-530.

Chiappori P.-A., Iyigun M., Weiss Y. (2009) Investment in Schooling and the Marriage Market // American Economic Review, vol. 99, no 5, pp. 1689-1713.

De Hauw D., Grow D., Van Bavel J. (2017) The Reversed Gender Gap in Education and Assortative Mating in Europe // European Journal of Population, vol. 33, pp. 445-474.

Eika L., Mogstad M., Zafar B. (2019) Educational Assortative Mating and Household Income Inequality // Journal of Political Economy, vol. 127, no 6, pp. 2795-2835.

Esteve A., Garci'a-Roma'n J., Permanyer I. (2012) The Gender-Gap Reversal in Education and Its Effect on Union Formation: The End of Hypergamy? // Population and Development Review, vol. 38, no 3, pp. 535-546.

Esteve A., Schwartz C.R., van Bavel J., Permanyer I., Klesment M., García-Román J. (2016) The End of Hypergamy: Global Trends and Implications // Population and Development Review, vol. 42, no 4, pp. 615-625.

Fernández R., Guner G., Knowles J. (2005) Love and Money: A Theoretical and Empirical Analysis of Household Sorting and Inequality // Quarterly Journal of Economics, vol. 120, no 1 , pp. 273-344.

Gihleb R., Lang K. (2016) Educational Homogamy and Assortative Mating Have not Increased // IZA DP. No. 10413.

Goldin C., Katz L., Kuziemko I. (2006) The Homecoming of American College Women: The Reversal of the College Gender Gap // Journal of Economic Perspectives, vol. 20, no 4, pp. 133-156.

Goldscheider F., Waite L. (1993) New Families, No Families? The Transformation of the American Home, Berkeley: University of California Press.

Greenwood J., Guner N., Kocharkov G., Santos C. (2014) Marry Your Like: Assortative Mating and Income Inequality // American Economic Review, vol. 104, no 5, pp. 348-353.

Isen A., Stevenson B. (2010) Women's Education and Family Behavior: Trends in Marriage, Divorce and Fertility // NBER. Working Paper No. 15725.

Kalmijn M. (2013) The Educational Gradient in Marriage: A Comparison of 25 European Countries // Demography, vol. 50, no 4, pp. 1499-1520. 
Lam D. (1988) Marriage Markets and Assortative Mating with Household Public Goods: Theoretical Results and Empirical Implications // Journal of Human Resources, vol. 23, no 4, pp. 462-487.

Lundberg S., Pollak R., Stearns J. (2016) Family Inequality: Diverging Patterns in Marriage, Cohabitation, and Childbearing // Journal of Economic Perspectives, vol. 30, no 2, pp. 79-102.

Nielson H., Svarer M. (2009) Educational Homogamy: How Much of Opportunities? // Journal of Human Resources, vol. 44, no 4, pp. 1066-1086.

Oppenheimer V. (1988) A Theory of Marriage Timing // American Journal of Sociology, vol. 94, no 3, pp. 563-591.

Schofer E., Meyer J. (2005) The Worldwide Expansion of Higher Education in The Twentieth Education Century // American Sociological Review, vol. 70, no 6, pp. 898-920.

Schwartz C., Mare R. (2005) Trends in Educational Assortative Marriage from 1940 to 2003 // Demography, vol. 42, no 4, pp. 621-646.

Schwartz C. (2010) Pathways to Educational Homogamy in Marital and Cohabiting Unions // Demography, vol. 47, no 3, pp. 735-753.

Schwartz C. (2013) Trends and Variation in Assortative Mating: Causes and Consequences // Annual Review of Sociology, no 39, pp. 451-470.

Sinkhorn R., Knopp P. (1967) Concerning Nonnegative Matrices and Doubly Stochastic Matrices // Pacific Journal of Mathematics, vol. 21, no 2, pp. 343-348.

Van Bavel J., Schwartz C., Esteve A. (2018) The Reversal of The Gender Gap in Education and Its Consequences for Family Life // Annual Review of Sociology, no 44, pp. 341-360.

\title{
Trends in Educational Assortative Mating in Russia: Do Changes in Educational Structure Matter? ${ }^{9}$
}

\author{
D. ZINCHENKO*, A. LUKYANOVA**
}

\begin{abstract}
*Daria Zinchenko - Master's in Economics, Research Intern, Center for Labor Market Studies, National Research University Higher School of Economics. Address: 20, Myasnitskaya St., Moscow, 101000, Russian Federation. E-mail: dzinchenko@hse.ru **Anna Lukyanova - PhD in Economics, Senior Researcher, Center for Labor Market Studies, National Research University Higher School of Economics. Address: 20, Myasnitskaya St., Moscow, 101000, Russian Federation. E-mail: alukyanova@hse.ru

Citation: Zinchenko D., Lukyanova A. (2021) Trends in Educational Assortative Mating in Russia: Do Changes in Educational Structure Matter? Mir Rossii, vol. 30, no 1, pp. 111-133 (in Russian). DOI: 10.17323/1811-038X-2021-30-1-111-133
\end{abstract}

\begin{abstract}
This paper studies the impact of educational upgrading on marital status and educational assortative mating. We use data from the Russian Longitudinal Monitoring Survey -
\end{abstract}

9 Funding: The reported study was funded by RFBR, project number 19-310-90071. 
HSE (RLMS-HSE) for 1995-2015. Our findings reveal a decline in the proportion of the population who are married for both men and women, at all education levels, and for most age groups. Educational upgrading restrained the decline in the proportion of the population who are married due to a rising share of higher educated groups who are more likely to marry. Women are now more likely to have husbands with lower education. Such an increase in educational hypogamy was accompanied by a reduction in homogamy. Nonetheless, educational homogamy remains the most prevalent marriage pattern. Adjustment for educational trends suggests that observed changes in educational assortative mating are driven by changes in the education structure while the odds for highly educated women of marrying down remained unchanged.

Keywords: Russia, education, gender, marriage, assortative mating, marital status, homogamy

\section{References}

Autor D., Dorn D., Hanson G. (2019) When Work Disappears: Manufacturing Decline and the Falling Marriage Market Value of Young Men. American Economic Review: Insights, vol. 1, no 2, pp. 161-178.

Becker G. (1973) A Theory of Marriage. Journal of Political Economy, vol. 81, no 4, pp. 813-846.

Bessudnov A.R., Kurakin D.Y., Malik V.M. (2017) Kak voznik i chto skryvaet mif o vseobshchem vysshem obrazovanii [The Myth about Universal Higher Education: Russia in the International Context]. Educational Studies, no 3, pp. 83-109.

Blossfeld H. (2009) Educational Assortative Marriage in Comparative Perspective. Annual Review of Sociology, vol. 35, pp. 513-530.

Chiappori P.-A., Iyigun M., Weiss Y. (2009) Investment in Schooling and the Marriage Market. American Economic Review, vol. 99, no 5, pp. 1689-1713.

De Hauw D., Grow D., Van Bavel J. (2017) The Reversed Gender Gap in Education and Assortative Mating in Europe. European Journal of Population, vol. 33, pp. 445-474.

Eika L., Mogstad M., Zafar B. (2019) Educational Assortative Mating and Household Income Inequality. Journal of Political Economy, vol. 127, no 6, pp. 2795-2835.

Esteve A., Garc1'a-Roma'n J., Permanyer I. (2012) The Gender-Gap Reversal in Education and Its Effect on Union Formation: The End of Hypergamy? Population and Development Review, vol. 38, no 3, pp. 535-546.

Esteve A., Schwartz C.R., van Bavel J., Permanyer I., Klesment M., García-Román J. (2016) The End of Hypergamy: Global Trends and Implications. Population and Development Review, vol. 42, no 4, pp. 615-625.

Fernández R., Guner G., Knowles J. (2005) Love and Money: A Theoretical and Empirical Analysis of Household Sorting and Inequality. Quarterly Journal of Economics, vol. 120, no 1 , pp. 273-344.

Gihleb R., Lang K. (2016) Educational Homogamy and Assortative Mating Have not Increased. IZA DP. No. 10413.

Goldin C., Katz L., Kuziemko I. (2006) The Homecoming of American College Women: The Reversal of the College Gender Gap. Journal of Economic Perspectives, vol. 20, no 4, pp. 133-156.

Goldscheider F., Waite L. (1993) New Families, No Families? The Transformation of the American Home, Berkeley: University of California Press.

Greenwood J., Guner N., Kocharkov G., Santos C. (2014) Marry Your Like: Assortative Mating and Income Inequality. American Economic Review, vol. 104, no 5, pp. 348-353. 
Gurko E.M. (2006) Predstavleniya studencheskoj molodezhi o brake [Students' Ideas about Marriage]. Aktual'nye problemy semej v Rossii [Current Problems of Families in Russia] (ed. Gurko T.A.), Moscow: IS RAS, pp. 200-210.

Gurko T.A., Mamikonyan M.S. (2018) Ustanovki studentov v brachno-semejnoj sfere i otnosheniyakh mezhdu polami [Students' Attitudes when It Comes to Marriage, Family and Relationships between Genders]. Vestnik Instituta sotziologii, vol. 9, no 4, pp. 192-226.

Isen A., Stevenson B. (2010) Women's Education and Family Behavior: Trends in Marriage, Divorce and Fertility. NBER. Working Paper No. 15725.

Kalmijn M. (2013) The Educational Gradient in Marriage: A Comparison of 25 European Countries. Demography, vol. 50, no 4, pp. 1499-1520.

Lam D. (1988) Marriage Markets and Assortative Mating with Household Public Goods: Theoretical Results and Empirical Implications. Journal of Human Resources, vol. 23, no 4, pp. 462-487.

Lundberg S., Pollak R., Stearns J. (2016) Family Inequality: Diverging Patterns in Marriage, Cohabitation, and Childbearing. Journal of Economic Perspectives, vol. 30, no 2, pp. 79-102.

Nielson H., Svarer M. (2009) Educational Homogamy: How Much of Opportunities? Journal of Human Resources, vol. 44, no 4, pp. 1066-1086.

Oppenheimer V. (1988) A Theory of Marriage Timing. American Journal of Sociology, vol. 94, no 3, pp. 563-591.

Roshchina Ya., Roshchin S. (2008) Brachnyj rynok v Rossii: vybor partnera i faktory uspekha [Marriage Market in Russia: Choice of Partner and Success Factors]. Matematicheskoe modelirovanie, no 4, pp. 21-37.

Schofer E., Meyer J. (2005) The Worldwide Expansion of Higher Education in The Twentieth Education Century. American Sociological Review, vol. 70, no 6, pp. 898-920.

Schwartz C., Mare R. (2005) Trends in Educational Assortative Marriage from 1940 to 2003. Demography, vol. 42, no 4, pp. 621-646.

Schwartz C. (2010) Pathways to Educational Homogamy in Marital and Cohabiting Unions. Demography, vol. 47, no 3, pp. 735-753.

Schwartz C. (2013) Trends and Variation in Assortative Mating: Causes and Consequences. Annual Review of Sociology, no 39, pp. 451-470.

Sinkhorn R., Knopp P. (1967) Concerning Nonnegative Matrices and Doubly Stochastic Matrices. Pacific Journal of Mathematics, vol. 21, no 2, pp. 343-348.

Soroko E. (2015) Etnicheski smeshannye supruzheskie pary v Rossijskoj Federatsii [Ethnically Mixed Families in the Russian Federation]. Demographic Review, no 4, pp. 96-123.

Van Bavel J., Schwartz C., Esteve A. (2018) The Reversal of The Gender Gap in Education and Its Consequences for Family Life. Annual Review of Sociology, no 44, pp. 341-360.

Volkov A.G. (2014) Izbrannye demograficheskie trudy [Selected Works on Demography: A Collection of Scientific Articles], Moscow: HSE.

Zakharov S.V. (2007) Transformatsiya brachno-partnerskikh otnoshenij v Rossii: «zolotoj vek» traditsionnogo braka blizitsya $\mathrm{k}$ zakatu? [Transformation of Marriage and Partnership in Russia: Is the "Golden Age" of Traditional Marriage Coming to an End?]. Roditeli i deti, muzhchiny i zhenshchiny v sem'e i obshchestve [Parents and Children, Men and Women in Family and Society] (eds. Maleva T.M., Sinjavskaya O.V.), Moscow: NISP, pp. 75-126.

Zinchenko D.I., Lukiyanova A.L. (2018) Assortativnost' brakov po obrazovaniyu i neravenstvo dohodov [Educational Assortative Mating and Income Inequality]. HSE Economic Journal, vol. 22, no 2, pp. 169-196. 